\title{
Energetic and Exergetic Performances Simulating of GSHP Greenhouse Cooling System in Northern China*
}

\author{
Lilong Chai ${ }^{1, * *}$, Chengwei Ma ${ }^{2, * * *}$, Gangyi $\mathrm{Xu}^{1}$, Mingchi Liu ${ }^{1}$, and Yong $\mathrm{Xu}^{1}$ \\ ${ }^{1}$ Vegetable Research Center, \\ Beijing Academy of Agriculture and Forestry Sciences, Beijing 100097, China \\ lchaipurdue@gmail.com \\ ${ }^{2}$ College of Water Conservancy \& Civil Engineering, China \\ Agricultural University, Beijing 100083, China \\ macwbs@cau .edu.cn
}

\begin{abstract}
The Energetic and Exergetic performances evaluating models were built for a agricultural greenhouse cooling with groundwater-style GSHP system (GSHPs) in Northern China. The Exergy destruction $\left(\right.$ Ex $\left._{\text {dest }}\right)$, Exergy efficiency $(\varepsilon)$ and coefficient of performance (COP) were estimated and presented based on summer cooling test monitored data and the simulation models. Analyzed results indicate that the evaporator has the highest Exergy efficiency compared with other sections of the system, which reached $92 \%$ during cooling test that means the evaporator has a brilliant performance of reversibility in cooling mode. The condenser and compressors have lower reversibility relatively. Generally, GSHPs has an Exergy efficiency of $36 \%$. Besides, COP of GSHPs cooling in greenhouse reached 3.09, which is higher than 2.0 of conventional air source heat pump systems COP by $50 \%$.
\end{abstract}

Keywords: greenhouse, Ground source heat pump, cooling, Exergy efficiency, COP.

\section{Introduction}

The utilizing of renewable and clean energy source, such as solar energy and shallow geothermal energy for building air-conditioning were conducted more frequent with the strengthen of global warming and environmental pollutant [1-4]. The shallow geothermal energy (the solar energy stored in shallow soil layer and groundwater) has been well developed and applied in cooling and heating industrial and civilian constructions by making use of ground source heat pump (GSHP) technology [5, 6], which has been proved with the characteristics of effective, environmental friendly and multi-functional of buildings heating, cooling and dehumidifying $[7,8]$, which is indeed one of the most fast growing clean energy utilizing air-conditioning

\footnotetext{
*This study was supported by the earmarked fund for Modern Agro-industry Technology Research System (CARS-25-D-04).

${ }^{* * *}$ Research Assistant.

${ }^{* * * *}$ Professor, Corresponding author.
} 
technologies at present. By the end of 2005, the utilization scale of ground source heat pump air-conditioning in resident or office buildings had reached $3000 \times 10^{4} \mathrm{~m}^{2}$ in mainland China [9], and some research on GSHP technology in agricultural facilities cooling or heating were conducted in recent years $[10,11]$.

Although the energy saving performance of GSHPs in greenhouse cooling or heating has been estimated in past studies with many methods [12-14], most of analysis were limited in first law of thermodynamics, which describes the heat quantity transfer process in GSHPS, such as the COP was calculated based on this method. However, the quality of energy utilizing was taken into consideration in Carnot Cycle based heat transferring process such as heat pump system [15]. The quality analysis of the energy was defined as Exergy analysis that is based on second law of thermodynamics and is the combination of Enthalpy and Entropy. Exergy can be described as the maximum amount of work that a thermodynamic system can achieved when it is reach equilibrium with the reference environment $[16,17]$. Exergy analysis method has been utilized in various fields [18]. Dincer [12] has come up with that the potential usefulness of Exergy in addressing and solving environmental problems as well as attaining sustainable development is crucial. Ozgener and Hepbasli [19] have assessed the relations between thermodynamic losses and capital costs for devices, and suggested possible generalizations in the relation. Generally, the Exergy analysis method was proved to be a more comprehensive method in assessing the energy transferring [20,21]. Therefore, the combined method of energetic and exegetic performances study on agricultural greenhouse cooling need to be built for the utilizing of GSHPs.

The objects of this study is but not limited to (1) build the energetic and exergetic performance estimating method and simulation models for agricultural greenhouse cooling with GSHPs. (2) presents GSHPs greenhouse cooling performances based on the theories of first and second laws of thermodynamics.

\section{Materials and Methods}

\subsection{GSHP Greenhouse Cooling System}

The GSHPs and tested greenhouse (Fig. 1) were located in the in Haidian district (latitude $39^{\circ} 40^{\prime} \mathrm{N}$ ) of Beijing of China. The GSHPs system had three principal circuits, as shown in Fig.2.

(i) Groundwater drawing and refilling part (there are five wells with the depth of about $100 \mathrm{~m}$, one water drawing well, four water refilling wells. The groundwater drawing and refilling circuit consisted of one water drawing well, four water refilling wells, a water drawing pump, and a water refilling pump. Each water pump had 11 $\mathrm{kW}$ rated input power and $33.2 \mathrm{~m} 3 \mathrm{~h}-1$ maximum water flow rate. The distances between the drawing well and refilling wells ranged from 100 to $300 \mathrm{~m}$;

(ii) GSHP energy enhancing circuit, which consisted of four Danfoss Hermetic scroll compressors connected in series. GSHP unit contained about $58 \mathrm{~kg}$ R22 refrigerant and had total capacity of $380 \mathrm{~kW}$ for heating and $450 \mathrm{~kW}$ for cooling, the rated power of the electric motor for each compressor was $16.08 \mathrm{~kW}$;

(iii) Heat transportation and fan coil heating units. This circuit contains many water circulating pipes and two water pumps. 

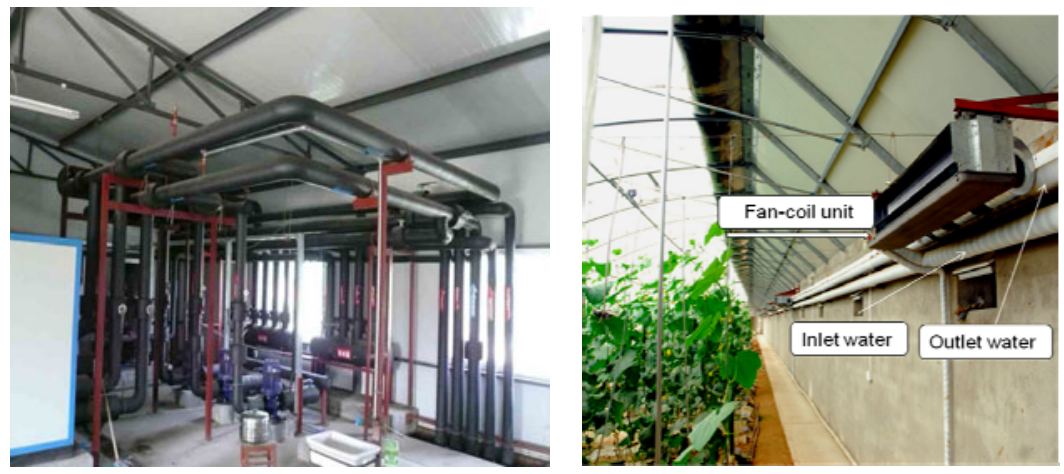

Fig. 1. GSHPs and agricultural greenhouse in test

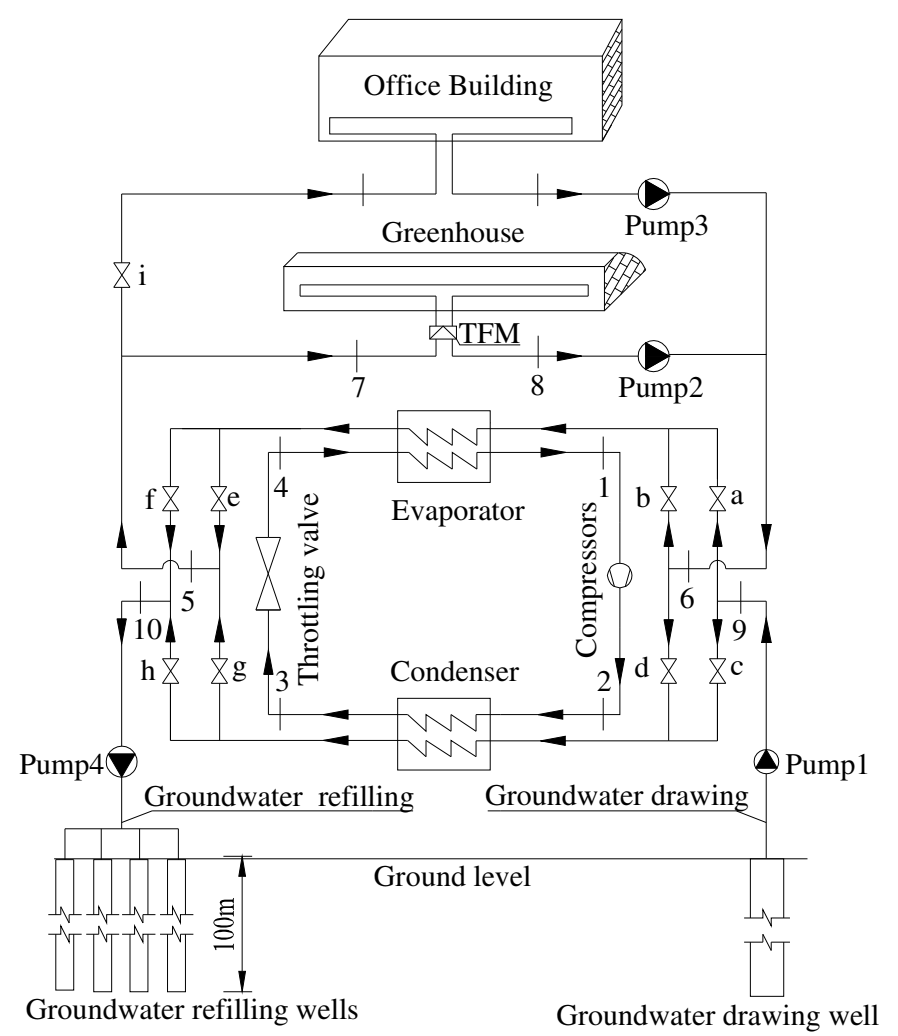

Fig. 2. Schematic diagram of GSHP cooling system in the study, a-i are valves installed on different water pipes; Pump1 represents the drawing water pumps; Pumps 2 and 3 represents circulating water pumps; Pump 4 represents backfilling water pumps; 1-10 represents each thermodynamic state position of refrigerant or water in each circle

During summer cooling test, the GSHPs operated cooling cycle, the water valves of $\mathrm{b}, \mathrm{c}, \mathrm{e}$ and $\mathrm{h}$ were turned on, and keep the valves of $\mathrm{a}, \mathrm{d}, \mathrm{f}$ and $\mathrm{g}$ shut off. In 
groundwater circle, the groundwater was drawn out from the well and pumped into heat exchanger connected with condenser via valve $\mathrm{c}$, and then was recharged back via valve $h$ to refilling wells after heat exchange in condenser. In greenhouse and building heating circle, the cold circulating water was sent to greenhouses and office buildings to cooling the house via valve e after released heat exchange in evaporator, and then was sent back via valve $b$ to the heat exchanger connected with evaporator.

\subsection{Energetic Performance Simulating Models}

The coefficient of performance (COP) was often used as indicator to analyze the GSHP system under cooling operation, which is an important index for evaluating the energy efficiency in a thermodynamics system. Referred to previous research [12, 21], the energy transfer and performance analytical model of the system can be put forwarded as Eqs. (1) - (7). The cooling COP of the GSHP unit, total system and greenhouse subsystem are analyzed in the study.

Groundwater,

$$
Q_{\text {well }}=m_{\text {well }}\left(h_{10}-h_{9}\right)
$$

Where, $Q_{\text {well }}$ is the groundwater heat transfer rate in condenser, in $\mathrm{kW} ; m_{\text {well }}$ is the mass flow rate of underground water, in $\mathrm{kg} \cdot \mathrm{s}^{-1} ; h_{9}$ is the specific enthalpy of underground water entering condenser, in $\mathrm{kJ} \cdot \mathrm{kg}^{-1} ; h_{10}$ is the specific enthalpy of groundwater leaving condenser, in $\mathrm{kJ} \cdot \mathrm{kg}^{-1}$.

Condenser,

$$
Q_{\text {cond }}=m_{\text {ref }}\left(h_{2 \mathrm{e}}-h_{3}\right)
$$

Where, $Q_{\text {cond }}$ is the heat rejection rate in the condenser, in $\mathrm{kW} ; m_{\text {ref }}$ is the mass flow rate of refrigerant $\mathrm{R} 22$, in $\mathrm{kg} \cdot \mathrm{s}^{-1} ; h_{2 \mathrm{e}}$ is the specific enthalpy of refrigerant leaving compressor/entering condenser in isentropic process, in $\mathrm{kJ} \cdot \mathrm{kg}^{-1} ; h_{3}$ is the specific enthalpy of refrigerant leaving condenser /entering throttling valve, in $\mathrm{kJ} \cdot \mathrm{kg}^{-1}$.

Evaporator,

$$
Q_{\text {evap }}=m_{\text {ref }}\left(h_{1}-h_{4}\right)
$$

Where, $Q_{\text {evap }}$ is the heat transfer rate in the evaporator, in $\mathrm{kW} ; h_{1}$ is the specific enthalpy of refrigerant leaving evaporator /entering compressor, in $\mathrm{kJ} \cdot \mathrm{kg}^{-1} ; h_{4}$ is the specific enthalpy of refrigerant leaving throttling valve /entering evaporator, in $\mathrm{kJ} \cdot \mathrm{kg}^{-1}$.

Compressor,

$$
W_{\text {comp }} \eta_{\mathrm{e}} \eta_{\mathrm{c}}=m_{\text {ref }}\left(h_{2 \mathrm{e}}-h_{1}\right)
$$

Where, $W_{\text {comp }}$ is the power input to the compressors in $\mathrm{kW} ; \eta_{\mathrm{e}}$ is the compressor isoentropy work efficiency; $\eta_{\mathrm{c}}$ is the compressor cubage work efficiency. In this study the product of $\eta_{\mathrm{e}}$ and $\eta_{\mathrm{c}}$ was considered as $75 \%$ as manufacturer rated.

Throttling valve,

$$
Q_{\text {thro }}=m_{\text {ref }}\left(h_{4}-h_{3}\right)
$$

Where, $Q_{\text {thro }}$ is the heat transfer rate in the throttling valve, in $\mathrm{kW}$.

$$
Q_{\text {cir }}=m_{\mathrm{wa}}\left(h_{6}-h_{5}\right)
$$


Where, $Q_{\mathrm{fc}}$ is the total heat transfer rate of circulating water system, in $\mathrm{kW} ; m_{\mathrm{wa}}$ is the mass flow rate of circulating water, in $\mathrm{kg} \cdot \mathrm{s}^{-1} ; h_{5}$ is the specific enthalpy of circulating water leaving evaporator, in $\mathrm{kJ} \cdot \mathrm{kg}^{-1} ; h_{6}$ is the specific enthalpy of circular water entering evaporator, in $\mathrm{kJ} \cdot \mathrm{kg}^{-1}$.

Circulating water system via greenhouse,

$$
Q_{\mathrm{fc}, \mathrm{g}}=m_{\text {wa }, \mathrm{g}}\left(h_{8}-h_{7}\right)
$$

Where, $Q_{\mathrm{fc}, \mathrm{g}}$ is the cooling capacity of fan-coil units in greenhouse, in $\mathrm{kW} ; m_{\mathrm{wa}, \mathrm{g}}$ is the mass flow rate of circulating water in greenhouse, in $\mathrm{kg} \cdot \mathrm{s}^{-1} ; h_{7}$ is the specific enthalpy of flowing in water in greenhouse, in $\mathrm{kJ} \cdot \mathrm{kg}^{-1} ; h_{8}$ is the specific enthalpy of flowing out water in greenhouse, in $\mathrm{kJ} \cdot \mathrm{kg}^{-1}$.

The COP was usually applied as an indicator for assessing the performance of GSHPs in civilian and industry buildings heating and cooling research [17, 22]. The greenhouse heating COP of GSHPs was estimated with Eqs. (8) -(10).

$$
\begin{gathered}
\mathrm{COP}_{\mathrm{GSHP}}=\frac{Q_{\text {evap }}}{W_{\text {comp }}} \\
E_{\mathrm{e}}=\sum_{i=1}^{n} \sum_{j=1}^{m} E_{i, j} \\
\mathrm{COP}_{\text {sys }}=\frac{E_{\mathrm{g}}}{3600 E_{\mathrm{e}}}
\end{gathered}
$$

Where, $E_{i, j}$ is the electricity energy consumed by equipment $j$ at time $i, \mathrm{kWh}$, the electricity energy consuming equipment in greenhouse cooling including GSHP compressors, water pumps, and fan coil units; $E_{e}$ is total electric energy consumed by GHSPs, $\mathrm{kWh} ; E_{\mathrm{g}}$ is cooling quantity in greenhouse provided by GHSPs, $\mathrm{kJ} ; \mathrm{COP}_{\mathrm{GSHP}}$ is cooling COP of GSHP unit, dimensionless; $\mathrm{COP}_{\text {sys }}$ is greenhouse cooling COP of GSHPs, dimensionless.

\subsection{Exergic Performance Simulating Models}

Exergy analysis is based on the second law of thermodynamics, which takes the entropy portion into consideration by including irreversibilities, and is the combination between enthalpy and entropy. Exergy reflects both quantity and quality of thermodynamic process $[12,13]$. The Exergy efficiency $\left(E x_{\text {dest }}\right)$ and Exergy destruction rate $(\varepsilon)$ are core content of Exergy analysis, which was applied in this study to demonstrate the performance of GSHPs in greenhouse and buildings cooling. The estimation of Exergy transferring in each section of GSHPs was conducted with Eqs. (11)- (17).

Compressor,

$$
e x_{2}-e x_{1}=\left(h_{2 \mathrm{i}}-h_{1}\right)-T_{0}\left(s_{2 \mathrm{i}}-s_{1}\right)
$$

Condenser,

$$
e x_{2}-e x_{3}=\left(h_{2 \mathrm{i}}-h_{3}\right)-T_{0}\left(s_{2 \mathrm{i}}-s_{3}\right)
$$

Throttle valve,

$$
e x_{3}-e x_{4}=\left(h_{3}-h_{4}\right)-T_{0}\left(s_{3}-s_{4}\right)
$$

Evaporator, 


$$
e x_{4}-e x_{1}=\left(h_{4}-h_{1}\right)-T_{0}\left(s_{4}-s_{1}\right)
$$

Heat exchanger of circulating water and evaporator,

$$
e x_{5}-e x_{6}=\left(h_{5}-h_{6}\right)-T_{0}\left(s_{5}-s_{6}\right)
$$

Heat exchanger of circulating water and greenhouse fan-coil units,

$$
e x_{7}-e x_{8}=\left(h_{7}-h_{8}\right)-T_{0}\left(s_{7}-s_{8}\right)
$$

Heat exchanger of groundwater and condenser,

$$
e x_{9}-e x_{10}=\left(h_{9}-h_{10}\right)-T_{0}\left(s_{9}-s_{10}\right)
$$

Where, $e x_{1} \sim_{10}$ represent the specific Exergy at each position of $1 \sim 10$ in Fig.2, in $\mathrm{kJ} \cdot \mathrm{kg}^{-}$ ${ }^{1} ; h_{1} \sim_{10}$ are the specific enthalpy at each position of $1 \sim 10$, respectively, in $\mathrm{kJ}^{\circ} \mathrm{kg}^{-1}$; $s_{1} \sim{ }_{10}$ are the specific entropy at each position of $1 \sim 10$, respectively, in $\mathrm{kJ} \cdot \mathrm{kg}^{-1} \cdot \mathrm{K}^{-1}$.

\subsubsection{Exergy Destruction Rate}

Exergy destruction rate embodies the quantity of devalued energy [13, 22], which was estimated with Eqs. (18) - (23) in each section of GSHPs.

Compressor,

$$
E x_{\text {dest }, \mathrm{comp}}=W_{\text {comp }}-m_{\text {ref }}\left(e x_{2}-e x_{1}\right)
$$

Condenser,

$$
E x_{\text {dest }, \text { cond }}=m_{\text {ref }}\left(e x_{9}-e x_{10}\right)-m_{\text {ref }}\left(e x_{3}-e x_{2}\right)
$$

Throttle valve,

$$
E x_{\text {dest }, \text { thro }}=m_{\text {ref }}\left(e x_{3}-e x_{4}\right)
$$

Evaporator,

$$
E x_{\text {dest,evap }}=m_{\text {ref }}\left(e x_{4}-e x_{1}\right)-m_{\text {ref }}\left(e x_{6}-e x_{5}\right)
$$

Groundwater circle,

$$
E x_{\mathrm{dest}, \mathrm{gw}}=Q_{\mathrm{well}}\left(1-\frac{T_{10}}{T_{0}}\right)-m_{\mathrm{well}}\left(e x_{10}-e x_{9}\right)
$$

Heat transportation circle,

$$
E x_{\text {dest,cir }}=Q_{\text {evap }}\left(1-\frac{T_{5}}{T_{0}}\right)-m_{\text {cir, } \mathrm{w}}\left(e x_{5}-e x_{6}\right)
$$

Where, $E x_{\text {dest,comp }}, E x_{\text {dest,evap, }} E x_{\text {dest,cond }}, E x_{\text {dest,thro, }} E x_{\text {dest,cir }}$ are exergy destruction rate in compressor, evaporator, condenser, throttling valve, circulating water system, respectively, dimensionless. $T_{5}, T_{6}, T_{9}$ are water temperatures at positions 5,6 and 9, respectively, in $\mathrm{K}$.

\subsubsection{Exergy Efficiency}

The Exergy efficiency of various sections and total system of GSHPs were estimated with the Eqs. (24)- (30).

Compressor,

$$
\varepsilon_{\mathrm{comp}}=\frac{E x_{2}-E x_{1}}{W_{\mathrm{comp}}}
$$


Throttle,

$$
\varepsilon_{\mathrm{thro}}=\frac{E x_{3}-E x_{4}}{W_{\mathrm{comp}}}
$$

Evaporator,

$$
\varepsilon_{\text {evap }}=1-\frac{E_{\text {dest,evap }}}{W_{\text {comp }}}
$$

Condenser,

$$
\varepsilon_{\text {cond }}=1-\frac{E_{\text {dest,cond }}}{W_{\text {comp }}}
$$

Circulating water system,

$$
\varepsilon_{\mathrm{cir}}=1-\frac{E_{\mathrm{dest}, \mathrm{cir}}}{W_{\mathrm{fc}}+W_{\mathrm{pump}, \mathrm{cir}}}
$$

GSHP unit,

$$
\varepsilon_{\mathrm{hp}}=1-\frac{E x_{\mathrm{dest}, \mathrm{evap}}+E x_{\mathrm{dest}, \mathrm{comp}}+E x_{\mathrm{dest}, \mathrm{thro}}+E x_{\mathrm{dest}, \mathrm{cond}}}{\frac{E x_{\mathrm{dest} \text { evap }}}{1-\varepsilon_{\text {evap }}}+\frac{E x_{\mathrm{dest}, \mathrm{comp}}}{1-\varepsilon_{\mathrm{comp}}}+\frac{E x_{\mathrm{dest} \text { thro }}}{1-\varepsilon_{\mathrm{thro}}}+\frac{E x_{\mathrm{dest}, \mathrm{cond}}}{1-\varepsilon_{\mathrm{cond}}}}
$$

GSHP system,

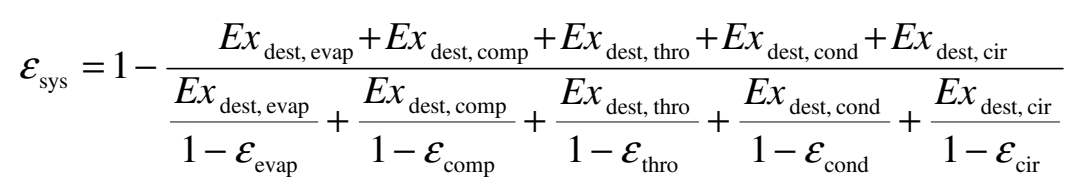

Where, $\varepsilon_{\text {comp }}, \varepsilon_{\text {evap }}, \quad \varepsilon_{\text {cond }}, \quad \varepsilon_{\text {thro }}, \quad \varepsilon_{\text {cir }}, \quad \varepsilon_{\text {hp }}, \quad \varepsilon_{\text {sys }}$ are Exergy efficiencies of the compressor, evaporator, condenser, throttle, circulating water system, GSHP unit and GSHP system respectively, dimensionless.

\subsection{Data Acquisition}

The following data was collected in this test,

(1) Measuring mass flow rates of the water by using rotameters (Beijing jingyuan liquid apparatus company, China). Rotameters were installed at inlet of all water flow tubes; 
(2) Measuring the temperature of the water inlet and outlet of the condenser, evaporator, and the greenhouse by using resistance thermometers PT1000 (Jingyuan liquid apparatus company, China, error limitation is $\pm(0.3+0.005 \Delta t$ $\left.{ }^{\circ} \mathrm{C}\right)$ ), each couple of thermometers were installed at inlet and outlet of water flow respectively;

(3) Measuring the temperature and humidity of air inside and outside of greenhouse by using temperature-humidity sensors RS-11 (ESPEC, Japan), the error limitation is $\pm 0.5{ }^{\circ} \mathrm{C}$ in temperature and $\pm 5 \%$ in relative humidity;

(4) Recording input power of different electric motor driving equipments by using ammeters (Shanghai Huaxia ammeters manufactory).

All the simulation calculation was conducted in Micro-soft Excel file. The results was calculated by following assumptions (i) The temperature at 1, 2, 3 and 4 points in GSHP unit was gained from manufacturer (Chongke High-Technology Development Co.,Ltd, Beijing,China), and assumed that the running was kept on steadily, as well as the temperature at 1,2,3 and 4 points. (ii) In this study, the restricted dead state was taken to be the state of environment, the temperature and the atmospheric pressure are $0{ }^{\circ} \mathrm{C}$ and $101.325 \mathrm{kPa}$, and don't take the Exergy destruction of water pumps and pressure change into account for the limited condition.

\section{Results and Discussion}

\subsection{The Energetic Performance of GSHPs}

For a great deal of water was needed for staff living and farm irrigation at experiment station in summertime, the pumped underground water were not backfilled into well during the test, and the Pump3 was not used in fact, so neglecting the effect of Pump3 and backfilled well. The refrigeration capacity of evaporator $Q_{\text {evap }}$ is $190 \mathrm{~kW}$, and the actual heat transfer rate between evaporator and circular water system was $164.15 \mathrm{~kW}$ on average according to the calculation based on the measurements made during Aug.13-18th, 2007, the power input is $53.32 \mathrm{~kW}$. Besides, the refrigeration capacity rate to greenhouse during test is $40.18 \mathrm{~kW}$ on average. Detailed information about the energy input and COP calculated results as shown in Table 1. The greenhouses cooling COP with GSHPs is 3.09, which is higher than air source heat pumps of 2.0 by more than $50 \%$ [22].

Table 1. Cooling performance of the GSHPs in greenhouse (Aug.13-18, 2007)

\begin{tabular}{ccc}
\hline Parameters & $\begin{array}{c}\text { GSHPs-Greenhouse } \\
\text { section }\end{array}$ & $\begin{array}{c}\text { GSHPs-whole } \\
\text { system }\end{array}$ \\
\hline Fan-coil unit cooling rate, $\mathrm{kW}$ & 40.2 & 157.2 \\
Heat exchanging rate of & - & 131.7 \\
Groundwater, kW & 8.1 & 32.2 \\
Compressors energy input rate, $\mathrm{kW}$ & 4.6 & 18.5 \\
Water pumps energy input rate, $\mathrm{kW}$ & 13.0 & 53.3 \\
Total energy input rate, $\mathrm{kW}$ & - & 5.90 \\
COP of Heat pump unit & 3.09 & 2.95 \\
COP of GSHPs & & \\
\hline
\end{tabular}




\subsection{Exergetic Performances}

Exergy analysis reflect the quality and quantity of a thermodynamic system, it is closely connected with each element of GSHP system, including compressor, evaporator, condenser and throttle valve. Exergy efficiencies and Exergy destruction are two of important indexes for evaluating energy utilizing system. The state of circulating water, groundwater and R-22 refrigerant was monitored or calculated according the test during Aug.13-18, 2007, as shown in Table 2.

Table 2. State parameters of Liquids in system (Aug.13-18th, 2007)

\begin{tabular}{|c|c|c|c|c|c|}
\hline Positions & Liquids & $\begin{array}{c}\text { Mass } \\
\text { flow rate } \\
m, \\
\mathrm{~kg} \cdot \mathrm{s}^{-1}\end{array}$ & $\begin{array}{c}\text { Temperature } \\
t, \\
{ }^{\circ} \mathrm{C}\end{array}$ & $\begin{array}{c}\text { Specific } \\
\text { enthalpy } \\
h, \\
\mathrm{~kJ} \cdot \mathrm{kg}^{-1}\end{array}$ & $\begin{array}{c}\text { Specific } \\
\text { entropy } \\
s, \\
\mathrm{~kJ} \cdot \mathrm{kg}^{-1} \cdot \mathrm{K}^{-1}\end{array}$ \\
\hline 1 & $\begin{array}{l}\text { R22 refrigerant in } \\
\text { vapor }\end{array}$ & 1.145 & 10.0 & 409 & 1.738 \\
\hline 2 & $\begin{array}{l}\text { R22 refrigerant in } \\
\text { vapor }\end{array}$ & 1.145 & 65.0 & 430 & 1.738 \\
\hline 3 & $\begin{array}{l}\text { R22 refrigerant in } \\
\text { Liquid }\end{array}$ & 1.145 & 35.0 & 243 & 1.146 \\
\hline 4 & $\begin{array}{l}\mathrm{R} 22 \text { refrigerant in } \\
\text { mixture of vapor and } \\
\text { liquid }\end{array}$ & 1.145 & 3.0 & 243 & 1.158 \\
\hline 5 & $\begin{array}{l}\text { Total circulating } \\
\text { water }\end{array}$ & $\begin{array}{l}15.03 \\
3\end{array}$ & $10.1 \pm 0.50$ & 42 & 0.152 \\
\hline 6 & $\begin{array}{l}\text { Total circulating } \\
\text { water }\end{array}$ & $\begin{array}{l}15.03 \\
3\end{array}$ & $12.7 \pm 0.55$ & 53 & 0.190 \\
\hline 7 & $\begin{array}{l}\text { Greenhouse inlet } \\
\text { circulating water }\end{array}$ & 0.923 & $10.2 \pm 0.48$ & 43 & 0.154 \\
\hline 8 & $\begin{array}{l}\text { Greenhouse outlet } \\
\text { circulating water }\end{array}$ & 0.923 & $20.8 \pm 0.83$ & 88 & 0.305 \\
\hline 9 & Groundwater & 9.220 & 14.1 & 59 & 0.211 \\
\hline 10 & Groundwater & 9.220 & 17.6 & 74 & 0.261 \\
\hline
\end{tabular}

Note, The state parameters value at different thermodynamic positions was calculated according to the recorded data during the test and published value [12, 22, 23] under rated compressor summer operating efficiency of $75 \%$.

In Exergetic performance simulating, the reference temperature $T_{\mathrm{o}}$ was set as averaged outdoor air temperature 306.25. The Exergetic performances including of Exergy destruction rate and Exergy efficiency of GSHPs were listed in Table 3. In GSHPs, the section of evaporator shows highest Exergy efficiency of 92.5, which indicates that this section has higher energy utilizing quality. The condensers Exergy efficiency is about $65.8 \%$. According to the Ozgener [22] reported result, the condenser has the Exergy efficiency of $80.5 \%$ when the GSHPs in heating mode, and $28.6 \%$ for evaporator. Therefore, the conclusion of higher Exergy efficiency for condenser and lower Exergy efficiency for evaporator in winter heating mode, and lower Exergy efficiency for condenser and higher Exergy efficiency for evaporator in summer cooling mode could be given. 
Table 3. Exergetic performances（Aug.13-18th, 2007）

\begin{tabular}{cccc}
\hline Elements & $\begin{array}{c}\text { Exergy destruction } \\
\text { rate, } \mathrm{kW}\end{array}$ & $\begin{array}{c}\text { Exergy destruction } \\
\text { efficiency, } \%\end{array}$ & $\begin{array}{c}\text { Exergy } \\
\text { efficiency, } \%\end{array}$ \\
\hline Compressor & 8.14 & 25.3 & 74.7 \\
Evaporator & 1.83 & 7.5 & 92.5 \\
Throttle valve & 11.22 & - & - \\
Condenser & 5.84 & 34.2 & 65.8 \\
Circulating water & 6.26 & 61.7 & 38.3 \\
system & 27.03 & 42.0 & 58.0 \\
GSHP unit & 33.29 & 64.0 & 36.0 \\
GSHP system &
\end{tabular}

Throttling valve consist of many capillaries, the Exergy destruction rate was high theoretically. As the R22 passing throttling valve was considered as adiabatic process, so the destruction of Exergy of R22 was caused by the increase of Entropy. Besides, as there no energy input in throttle valve, so the Exergy efficiency of throttling valve could be positive infinity or negative infinity, the study on it is insignificance. If the throttle valve was replaced with Expansion valve, the Entropy increase of R22 would be declined, but the cost of GSHPs would increase. The key object of energetic and exergetic performance analysis is to balance the relationship between economics and thermodynamics.

Generally, the total Exergy efficiency of GSHPs in greenhouse cooling is $36 \%$, which is higher than published value of $15 \%$ [23] in residential buildings cooling. However, the Exergy efficiency of GSHPs in this study has the potential to be improved by reducing the Exergy destruction of water circulating and fan-coil units operating.

\section{Conclusions}

The following conclusions were drawn based on the results in this study,

1) The Enegetic and Exergetic simulation models and performance evaluating method were built in this study for greenhouse GSHPs performance analysis;

2) According to simulated results, total Exergy efficiency of GSHPs in greenhouse cooling is $36 \%$, which is higher than published value of $15 \%$ in residential buildings cooling. The Exergy efficiency of GSHPs in this study has the potential to be improved by reducing the Exergy destruction of water circulating and fan-coil units operating.

3) The Energetic and Exergetic performances of GSHPs are associated with the economical performance closely, the optimizing of the Exergy reversibility and COP usually at the cost of economic performance degradation. The key object of energetic and exergetic performance analysis is to balance the relationship between economics and thermodynamics.

Acknowledgments. This study was supported by the earmarked fund for Modern Agro-industry Technology Research System (CARS-25-D-04). 


\section{References}

1. Zheng, D.: Modeling of standing column well in ground source heat pump system. Ph.D Thesis, Oklahoma State University, Stillwater (2004)

2. Mao, H., Wang, X., Wang, D.: The design and test of greenhouse solar energy heating system. Acta Energiae Solaris Sinica 25(3), 305-309 (2004)

3. Michopoulos, A.: Three-years operation experience of a ground source heat pump system in Northern Greece. Energy and Buildings 39, 328-334 (2007)

4. Ptasinski, J., Prins, M.J., Pierik, A.: Exergetic evaluation of biomass gasification. Energy 32, 568-574 (2007)

5. Zeng, H., Diao, N., Fang, Z.: A finite line-source model for boreholes in geothermal heat exchangers. Transfer-Asian Research 31(7), 558-567 (2002)

6. Hamada, Y., Nakamura, M., Saitoh, H., et al.: Improved underground heat exchanger by using no-dig method for space heating and cooling. Renewable Energy 32(3), 480-495 (2007)

7. Li, X., Chen, Z., Zhao, J.: Simulation and experiment on the thermal performance of U-vertical ground coupled heat exchanger. Applied Thermal Engineering 26, 1564-1571 (2006)

8. Karlsson, F., Fahlén, P.: Capacity-controlled ground source heat pumps in hydronic heating systems. International Journal of Refrigeration 30, 221-229 (2007)

9. $\mathrm{Xu}, \mathrm{W}$.: Investigation and analysis on utilization of ground source heat pump in China. Construction and Design for Project 12, 16-19 (2006)

10. Chai, L., Ma, C., Zhang, Y., et al.: Energy consumption and economic analysis of ground source heat pump used in greenhouse in Beijing. Transactions of the CSAE 26(3), 249-254 (2010)

11. Fang, H., Yang, Q., Sun, J.: Application of ground-source heat pump and floor heating system to greenhouse heating in winter. Transactions of the CSAE 24(12), 145-149 (2008)

12. Dincer, I.: The role of Exergy in energy policy making. Energy Policy 30, 137-149 (2002)

13. Sciubba, E., Ulgiati, S.: Emergy and Exergy analysis, Complementary methods or irreducible ideological options. Energy 30, 1953-1988 (2005)

14. Winter, C.-J.: Energy efficiency, no, It's Exergy efficiency. International Journal of Hydrogen Energy 32, 4109-4111 (2007)

15. Miu, D.: Refrigeration Compressor. China Machine Press, Beijing (2002) (in Chinese)

16. Zhang, J.: Brief Manual for Air Conditioning Worker. China Machine Press, Beijing (1999) (in Chinese)

17. Yan, J., Wang, Y.: Engineering Thermodynamics, 3rd edn. Higher Education Press, Beijing (2001)

18. Som, K., Datta, A.: Thermodynamic irreversibilities and Exergy balance in combustion. Progress Energy Combustion Science 34(3), 351-376 (2008)

19. Ozgener, O., Hepbasli, A.: Exergoeconomic analysis of a solar assisted ground-source heat pump greenhouse heating system. Applied Thermal Engineering 25, 1459-1471 (2005)

20. Bisio, G., Rubatto, G.: Work and entropy production aspects of irreversible processes in closed and steady-state open systems. Exergy, an International Journal 2, 192-205 (2002)

21. Ebru, K.A., Hepbasli, A.: A comparative study on exergetic assessment of two groundsource (geothermal) heat pump systems for residential applications. Building and Environment 42, 2004-2013 (2007)

22. Ozgener, O., Hepbasli, A.: A parametrical study on the energetic and exergetic assessment of a solar-assisted vertical ground-source heat pump system used for heating a greenhouse. Building and Environment 42, 11-24 (2007)

23. Zhao, H., Yang, Z.: The thermodynamic analysis of water source heat pump. Energy Conservation Technology 22(3), 29-32 (2004) (in Chinese) 